\title{
Comprehensive Analysis to Uncover Determinants of Patient Appointment Compliance in Ophthalmology at the Kresge Eye Institute, USA
}

This article was published in the following Dove Press journal: Patient Preference and Adherence

\author{
Alisha Khambati ${ }^{1}$ \\ Lauren Dowell' \\ Jahan Tajran' \\ Daniel Juzych ${ }^{2}$ \\ Sarah Syeda ${ }^{2}$ \\ M Roy Wilson ${ }^{2}$ \\ Mark S Juzych (iD ${ }^{2}$ \\ Ashok Kumar ${ }^{2}$ \\ 'School of Medicine, Wayne State \\ University, Detroit, MI, 4820I, USA; \\ ${ }^{2}$ Department of Ophthalmology, Visual \\ and Anatomical Sciences, Wayne State \\ University School of Medicine, Detroit, \\ MI, 4820I, USA
}

Introduction: Appointment compliance (AC) has a significant impact on patient care; however, determinants of AC in Ophthalmology and its subspecialties remains elusive.

Methods: We performed a five-year retrospective analysis across Kresge Eye Institute (KEI) and its affiliated Michigan locations. A total of 597,364 appointments across $>13$ subspecialties were included. AC was the primary outcome of interest. Compliant (CO) and noncompliant (NC) groups were compared to the following variables: patient characteristics (gender, race, age, insurance), appointment rank (relative to patient history), scheduling location, month, and ophthalmic specialty, in regard to arrival and no-show.

Results: Among all appointments, 59.77\% were associated with a female patient and $79.16 \%$ of the total number of appointments depicted patient compliance. AC differed concerning specialty, with retina representing the highest compliance across all appointments. Among 200+ insurance providers, Medicare was most frequently used and represented the highest share of $\mathrm{CO}$ appointments. African Americans were the primary ethnicity served by KEI and had the highest number of NC appointments.

Conclusion: Our study demonstrates the impact of patient demographics, appointment characteristics, and ophthalmic subspecialty on AC. A better understanding of these determinants could allow for an increased $\mathrm{CO}$ for Ophthalmology practices.

Keywords: retrospective, demographics, ophthalmology, appointment compliance

\section{Introduction}

The patient-physician relationship is an essential component of effective healthcare. ${ }^{1}$ However, to build this strong bond, it requires a long-standing relationship with the continuity of care and patient compliance with their appointments. ${ }^{2}$ The continuity of care is defined by the collaborative effort between patient and physician to create high quality and cost-effective healthcare. ${ }^{3}$ A prior study by Kim et al highlighted the significance of a longitudinal relationship between patients and physicians in the continuity of care. ${ }^{4}$ Specifically, their research suggests that a longer patient-physician relationship can reduce institutional and hospital financial costs, while also improving the medical outcomes for the patient. ${ }^{4,5}$ Continuity of care is considered an important indicator of patient satisfaction and essential in the development of trust. By improving this relationship, better patient compliance with their appointments can be achieved. 5,6

Several studies have described the importance of appointment compliance (AC) with respect to healthcare interventions intended to reduce hospitalizations,
Correspondence: Mark S Juzych; Ashok Kumar

Department of Ophthalmology, Visual and Anatomical Sciences, Wayne State University School of Medicine, 4717

St. Antoine, Detroit, MI, 4820I, USA

Tel + I 313 577-62 I3

Fax + I 313 577-778I

Email mjuzych@med.wayne.edu;

akuma@med.wayne.edu 
morbidity, and mortality risk..$^{7-9}$ Nwabuo et al discussed the effects of non-compliance (NC) on a patient's mortality risk. About $20 \%$ of surveyed patient participants were non-compliant to at least $30 \%$ of their appointments. ${ }^{8}$ Their results found a correlation between decreased patient attendance to their appointments and uncontrolled hypertension, and thus, potentiated a higher mortality risk. ${ }^{8}$

In the field of Ophthalmology, continuity of care and AC are important variables in the successful management of patients. Specialty-specific diagnoses, such as glaucoma, require frequent clinic visits due to their high prevalence across the US population. ${ }^{10,11} \mathrm{AC}$ is also important in the early detection and treatment of pathologies that can result in blindness, eg, diabetic retinopathy, age-related macular degeneration, and glaucoma. ${ }^{11-14}$ It is therefore important to investigate the various patient and clinical characteristics that drive AC. For example, studies have shown that AC can vary by ophthalmological diagnoses. ${ }^{10}$ Zebardast et al, ${ }^{10}$ reported an $\mathrm{AC}$ rate of $52 \%$ among patients with diabetic retinopathy following an initial diabetic eye examination, $81 \%$ in patient's post-cataract surgery, and $83 \%$ for a followup examination after an initial diagnosis of primary openangle glaucoma. ${ }^{10}$

To improve the quality of patient care, information on the factors which have impacted patient compliance should be explored and raise awareness to healthcare providers. ${ }^{9}$ Our retrospective study, which is focused on patients who sought care at Kresge Eye Institute (KEI) in Detroit, Michigan, is aimed to elaborate on factors impacting AC and continuity of care. The Detroit metropolitan area has a diverse population, with a wide range of demographics, and stratified income brackets. ${ }^{15}$ This provided the necessary framework needed to properly assess patient appointment compliance. The demographic data utilized in this study included: KEI clinic locations and providers, physician specialty, the chronological rank of appointments within a patient's appointment history, age, race, insurance, zip code, and gender. This data provided by KEI offers insight into the factors contributing to appointment compliance and continuity of care.

\section{Methods}

\section{Statement of Ethics}

The Institutional Review Board of Wayne State University approved the study protocol (IRB-20-04-2048); as this study was retrospective with no patient identifiers, patient consent was waived. The study was conducted in accordance with the Declaration of Helsinki and is HIPAA-compliant. We certify that all patient medical history will remain confidential.

\section{Study Design (Inclusion and Exclusion Criteria)}

Appointment data in electronic medical records (EMR) was collected across a five-year period (January 1, 2014 to December 31,2018 ) on patients who had visited any of KEI's 24 out-patient affiliated clinic locations in Michigan. Only patients aged 18 years or older with a Michiganbased zip code (48XXX and 49XXX) were included in this study. Statistical analysis was restricted to appointments in which the patient was an arrival or no-show. Canceled appointments, as well as any appointments classified as testing or spontaneous were excluded from analysis. An appointment was determined to be spontaneous if it was associated with an emergency clinic.

\section{Variables Definition and Data Collection}

The EMR was used to classify patient arrival to appointment as compliant (CO) and patient cancellation or noshow to appointment as non-compliant (NC). Appointment rank was defined as the relative chronological rank of each appointment within the associated patient's appointment history. Patient demographics and information regarding their clinical visit were determined through their medical records. These characteristics include patient age, race/ ethnicity, gender, primary insurance type, appointment location, month, and ophthalmic specialty visited. The ophthalmic specialty visited was determined by the specialty of the billing physician.

\section{Statistical Analyses}

Stata MP 16.1 (StataCorp LLC, College Station, TX, USA) was used to perform all statistical analyses. All analyses were performed across a dataset consisting of all appointments as unique observations. Also, the percent appointment compliance was calculated according to the patient's entire appointment history at KEI.

A comprehensive table, consisting of absolute and relative frequencies, was generated to describe appointment characteristics relative to AC. The Chi-square test was performed to compare categorical and binary characteristics between $\mathrm{CO}$ and $\mathrm{NC}$ groups for patient gender, race, and insurance type as well as scheduling location, appointment month, provider, and physician specialty. The Mann-Whitney $U$-test was 
applied to assess the relative distribution of continuous characteristics (including patient age and appointment rank) across $\mathrm{CO}$ and $\mathrm{NC}$ appointments. ${ }^{16}$ The appointment rank variable was used as an indicator of the patient's relationship length with KEI at each appointment relative to all the appointments in a patient's appointment history.

Central values of tendency, corresponding to the mean, median, IQR, 95\% CI of associated odds ratios, and p-values were determined to further define the continuous variables. Multiple logistic regression with AC as the dependent variable and patient and appointment characteristics as independent variables was performed to assess predictors while controlling for covariates. Receiver operating characteristic (ROC) curves with area under curve (AUC) values and Hosmer-Lemeshow goodness of fit tests were generated from logistic regression analyses to demonstrate the predictive accuracy and fit of our model. A p-value $<0.05$ was used to establish statistical significance.

Appointment frequencies were graphed according to ophthalmic specialty and patient race. To demonstrate the population from which we sampled, a geographical map the entire population of appointments scheduled at KEI was generated using Microsoft ${ }^{\circledR}$ Excel Version 15.11.2 (Microsoft, Redmond, WA, USA) to demonstrate the relative frequency of appointments according to each associated patient's residential zip code (when available)

\section{Results}

A total of 836,384 appointments occurred within the fiveyear period across 24 out-patient Michigan-based KEI affiliated clinic locations. Using the previous inclusion criteria, 7360 out of state, 198,846 appointment cancellations, 12,804 testing, 9442 pediatric, and 10,578 appointments were excluded. A total of 597,364 appointments were included in this analysis (Figure 1).

\section{Cumulative Characteristics}

Cumulatively, $79.16 \%(472,860)$ of all appointments (Table 1) were compliant. Percent compliance was calculated according to each patient's entire appointment history and the mean was found to be $70.37 \%$ (Table 2). There were more than 13 ophthalmic specialties represented as is summarized in Figure 2 with the corresponding frequencies.

The mean patient age across all appointments was 58.01 years (SD: 20.07 years) with a range of $<1$ year to 118 years (IQR: 48.09-71.52 years) (Table 2). While more than ten racial categories were represented, $61.02 \%$ of appointments at KEI were for African American patients. The frequency of racial demographics is highlighted in Figure 3. For sex distribution, the majority $(59.77 \%$; 356,966 ) of appointments were those of female patients. The patient zip code associated with each appointment was

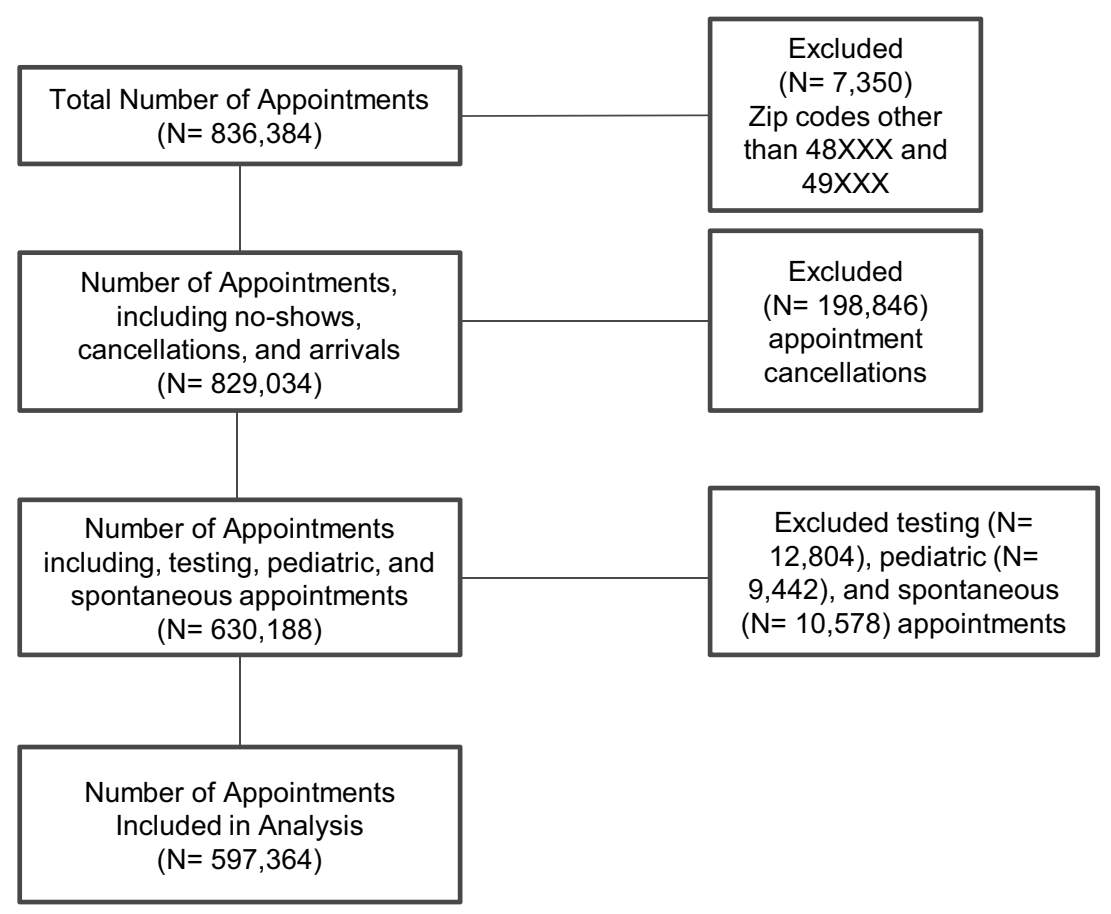

Figure I Study design with inclusion and exclusion criteria. 
Table I Distribution of Demographic, Administrative, and Appointment Characteristics Among Compliant and Non-Compliant Appointments at $\mathrm{KEI}$

\begin{tabular}{|c|c|c|c|}
\hline & Non-Compliant & Compliant & \multirow[t]{2}{*}{ p-value } \\
\hline & $n=124,504(20.84 \%)$ & $n=472,860(79.16 \%)$ & \\
\hline \multicolumn{4}{|l|}{ Demographic Characteristics } \\
\hline Female sex, No. (\%) & $73,650(59.23 \%)$ & $283,316(59.92 \%)$ & $<0.0001$ \\
\hline \multicolumn{3}{|c|}{ Race (distribution of 5 categories with highest frequency) } & \multirow[t]{6}{*}{$<0.0001$} \\
\hline African American/Black & $91,335(73.36 \%)$ & $273,168(57.77 \%)$ & \\
\hline Asian & 1725 (1.39\%) & 9098 (1.92\%) & \\
\hline Caucasian/White & $12,612(18.13 \%)$ & $151,108(31.96 \%)$ & \\
\hline Hispanic or Latino & 2408 (1.93\%) & 8951 (1.90\%) & \\
\hline Middle Eastern & $3697(2.97 \%)$ & $14,489(3.06 \%)$ & \\
\hline Age, Mean (IQR) & $51.88(40.91-65.20)$ & $59.61(50.54-72.86)$ & $<0.00001$ \\
\hline \multicolumn{3}{|c|}{ Ophthalmic specialty (distribution of 5 categories with highest frequency) } & \multirow[t]{6}{*}{$<0.0001$} \\
\hline Comprehensive & $24,781(19.90 \%)$ & $104,399(22.08 \%)$ & \\
\hline Retina & $16,208(13.02 \%)$ & II2,797 (23.84\%) & \\
\hline Resident or Fellow & $30,169(24.23 \%)$ & $79,533(16.82 \%)$ & \\
\hline Glaucoma & $18,040(14.49 \%)$ & $76,563(16.19 \%)$ & \\
\hline Cornea & $9596(7.71 \%)$ & $32,498(6.87 \%)$ & \\
\hline \multicolumn{4}{|l|}{ Administrative Characteristics } \\
\hline \multicolumn{3}{|c|}{ Appointment Location (distribution of 3 categories with highest frequency) } & \multirow[t]{4}{*}{$<0.0001$} \\
\hline KEI General & $44,898(36.06 \%)$ & $167,810(35.49 \%)$ & \\
\hline Residents & $33,005(26.51 \%)$ & $84,524(17.88 \%)$ & \\
\hline KEI Southfield & $6594(5.30 \%)$ & $40,909(8.65 \%)$ & \\
\hline \multicolumn{3}{|c|}{ Appointment Month (distribution of 3 categories with highest frequency) } & \multirow[t]{4}{*}{$<0.0001$} \\
\hline March & $\mathrm{II}, \mathrm{I} 05$ (8.92\%) & $42,631(9.02 \%)$ & \\
\hline June & $10,997(8.83 \%)$ & $4 I, \mid 76$ (8.7I\%) & \\
\hline April & $10,457(8.40 \%)$ & $40,623(8.59 \%)$ & \\
\hline \multicolumn{3}{|l|}{ Scheduling Provider } & $<0.0001$ \\
\hline \multicolumn{3}{|c|}{ Primary Insurance Types (distribution of 3 categories with highest frequency) } & \multirow[t]{4}{*}{$<0.0001$} \\
\hline Medicare Associated & $38,185(31.14 \%)$ & $209,484(44.41 \%)$ & \\
\hline Molina Associated & $15,038(12.26 \%)$ & $33,033(7.00 \%)$ & \\
\hline Blue Cross Blue Shield Associated & $\mathrm{II}, 742(9.57 \%)$ & $67,811(14.38 \%)$ & \\
\hline \multicolumn{4}{|l|}{ Appointment Characteristics } \\
\hline Appt rank number, Mean (IQR) & $7.58(2-9)$ & $10.10(2-13)$ & $<0.00001$ \\
\hline
\end{tabular}

used to determine the distribution of appointments per patient zip code (Figure 4).

\section{Demographic Characteristics}

Patient demographic and clinical characteristics are described relative to AC across all appointments, which are summarized in Table 1. Patient gender had significant differences between $\mathrm{CO}$ and $\mathrm{NC}$ groups $(\mathrm{p}<0.0001)$ with female patients representing a significantly greater portion of all compliant appointments. CO appointments were associated with significantly ( $\mathrm{p}<0.00001)$ older patients as compared to NC appointments (Tables 1 and 2). AC was found to have a significantly different distribution across the 10 racial categories analyzed $(\mathrm{p}<0.0001$; Table 1$)$ 
Table 2 Summary of Continuous Appointment Characteristics

\begin{tabular}{|l|c|c|c|c|}
\hline \multirow{2}{*}{ Age (years) } & & Mean & Range & Med (IQR) \\
\cline { 2 - 5 } & CO & 59.61 & $0.002-116$ & $62.97(50.54-72.86)$ \\
\cline { 2 - 5 } & All & 51.88 & $0.008-118$ & $54.87(40.91-65.20)$ \\
\hline \multirow{3}{*}{ Appt Rank } & CO & 10.10 & $1-175$ & $61.36(48.09-71.52)$ \\
\cline { 2 - 5 } & NC & 7.58 & $1-143$ & $6(2-13)$ \\
\cline { 2 - 5 } & All & 9.58 & $1-175$ & $4(2-9)$ \\
\cline { 2 - 5 } & CO & $70.37 \%$ & $4.17-100 \%$ & $71.43 \%(25.00-83.33 \%)$ \\
\cline { 2 - 5 } & NC & $37.80 \%$ & $0-95.83 \%$ & $40.00 \%(17.65-57.14 \%)$ \\
\cline { 2 - 5 } & All & $63.58 \%$ & $0-100 \%$ & $66.67 \%(50.00-80.00 \%)$ \\
\hline \multirow{2}{*}{ Potal Number of Appointments per Patient's Entire History } & CO & 19.53 & $1-175$ & $14(6-26)$ \\
\cline { 2 - 5 } & NC & 12.73 & $1-175$ & $7(3-17)$ \\
\cline { 2 - 5 } & All & 18.12 & $1-175$ & $12(5-24)$ \\
\hline
\end{tabular}

Clinic and Administrative Characteristics The distribution of the 24 associated clinic locations and appointment month significantly differed concerning AC $(\mathrm{p}<0.0001$; Table 1$)$. Also, the distribution of primary insurance types across more than 200 possible insurance types and ophthalmic specialty differed significantly with

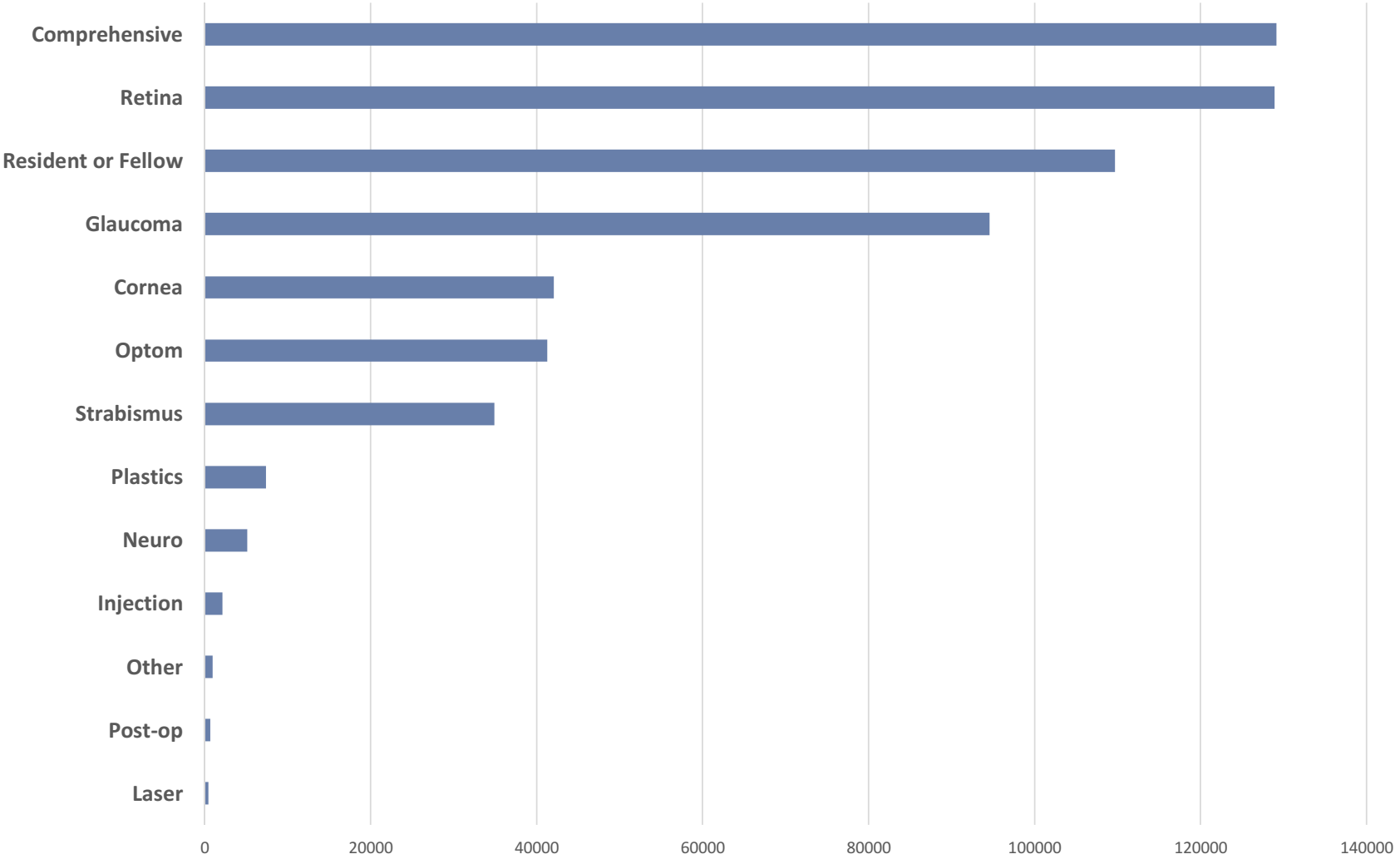

Figure 2 Frequency of appointments per ophthalmology subspecialty. The total $n=597,364$ appointments were categorized across the indicated ophthalmic subspecialties seen at the KEI clinics. 


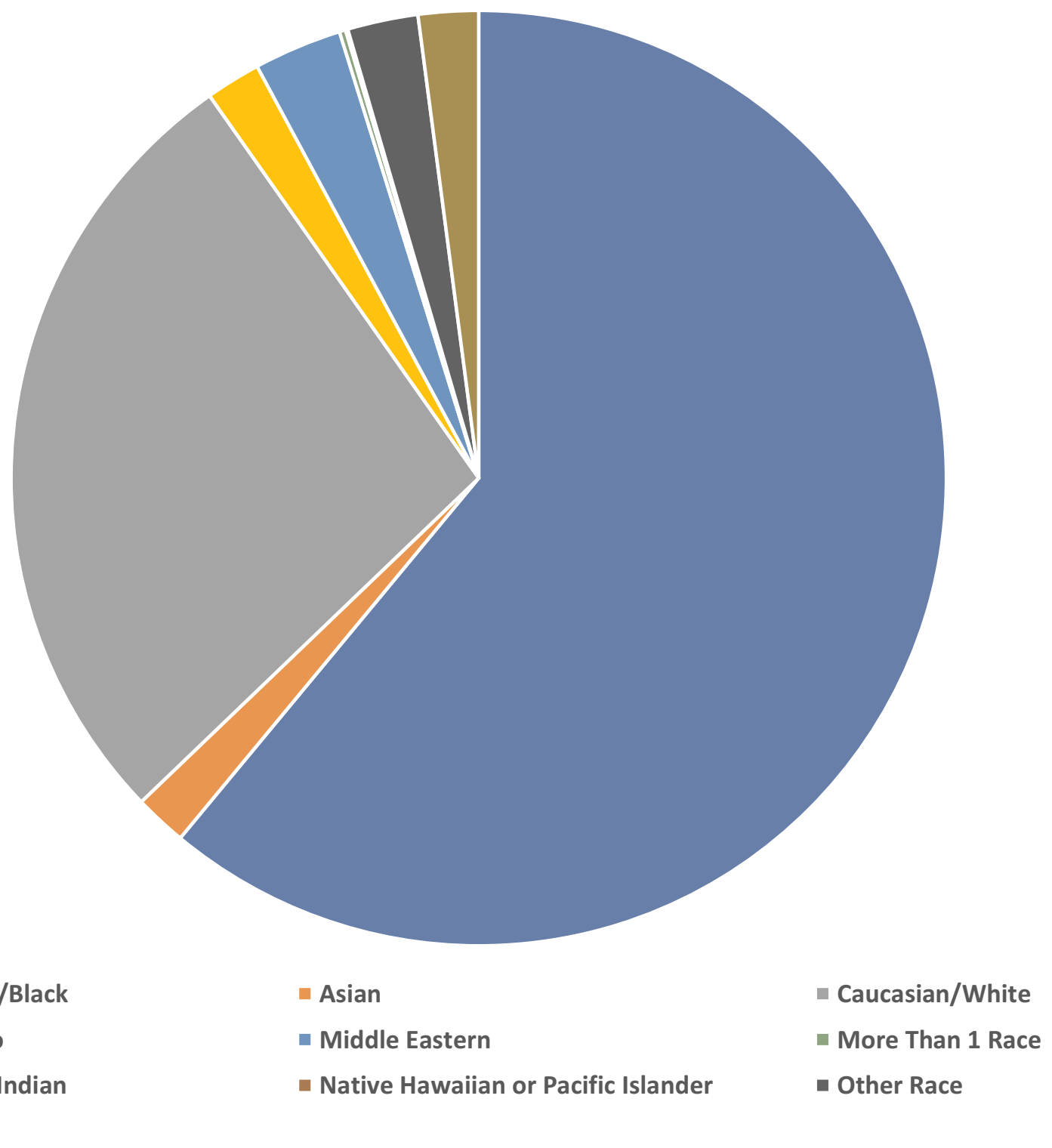

Figure 3 Frequency of appointments per racial category. The total $n=597,364$ appointments were categorized across the indicated racial categories seen at the KEl clinics.

respect to AC $(\mathrm{p}<0.0001)$. CO appointments were associated with a significantly higher appointment rank $(\mathrm{p}<0.00001$; Table 1) than NC appointments.

\section{Regression Analysis}

Multiple logistic regression analysis was performed to control for covariates and build a model which the greatest predictive accuracy possible from the data available. Our model features the categorical contribution of each racial group, ophthalmic specialty, clinic location, primary insurance type, and appointment month relative to AC. Reference categories were determined based on the greatest frequency. The results of the model are found in Table 3 with an associated ROC curve and AUC in Figure 5 and Supplementary Data.

Multiple logistic regression revealed age, male sex, appointment rank, appointment month, race, specialty, and clinic location to be significantly associated with $\mathrm{AC}$ with the AUC to be equal to 0.75 (Table 3 and Figure 5). An additional logistic regression for primary insurance type compared to $\mathrm{AC}$ was performed and is found in the supplementary materials. Across all racial categories reported relative to African Americans, appointments associated with patient's whose race was unknown had the lowest odds of compliance (OR: 0.10 ; 95\% CI: 0.09 $0.12 ; \mathrm{p}<0.0001)$ and appointments of Caucasians had the 


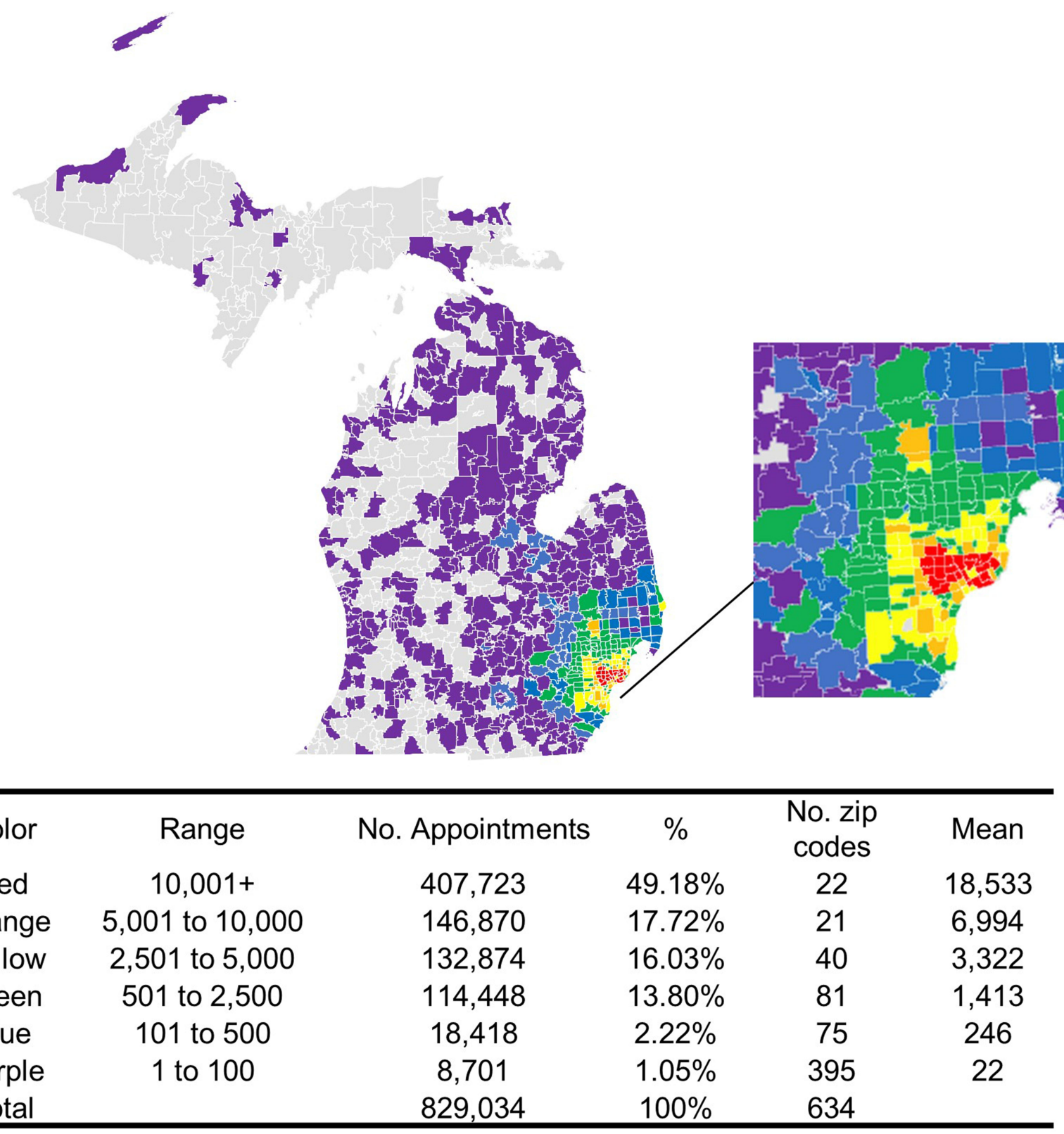

Figure 4 Appointment frequency across each zip code. The total $n=829,034$ appointments were mapped across each Michigan-based zip code using Microsoft Excel (see Methods section). The enlarged area represents metro Detroit.

Note: Four observations in our analysis were Michigan-based, but had an unspecified zip code listed in the EMR at that appointment.

highest odds of compliance (OR: $2.82 ; 95 \%$ CI:2.59-3.07; $\mathrm{p}<0.0001)$.

\section{Discussion}

Appointment compliance is important for a multitude of reasons. If a patient fails to show up for their appointment, it can result in decreased clinic efficiency, financial losses, and can inhibit the formation or maturation of the patient-physician relationship. ${ }^{17,18}$ In other words, a patient's lack of attendance can bear a financial impact on both service and opportunity costs. ${ }^{17,18}$ Due to these potential consequences, studies continue to investigate strategies to help improve AC. This can include actions such as various methods to remind patients about their appointment eg, regular mailings, emails, phone calls, and SMS reminders. ${ }^{7,19,20}$ Peck et al, ${ }^{9}$ analyzed both patient and appointment-specific characteristics to allow clinicians and healthcare systems to implement targeted patient support initiatives with the hopes of increasing $\mathrm{AC}{ }^{9}$ 
Table 3 Comprehensive Multiple Logistic Regression Across Initial Appointments

\begin{tabular}{|c|c|c|c|}
\hline Predictor* & $\begin{array}{l}\text { Odds } \\
\text { Ratio }\end{array}$ & P-value & $95 \% \mathrm{Cl}$ \\
\hline \multicolumn{4}{|l|}{ Patient Race } \\
\hline African American & \multicolumn{3}{|c|}{ Reference category } \\
\hline Race Unknown & 0.10 & $<0.0001$ & $0.09-0.12$ \\
\hline Asian & 1.89 & $<0.0001$ & $1.54-2.33$ \\
\hline Caucasian/White & 2.82 & $<0.0001$ & $2.59-3.07$ \\
\hline Hispanic/Latino & 1.58 & $<0.0001$ & $1.44-1.73$ \\
\hline Middle Eastern & 1.65 & $<0.0001$ & $1.48-1.84$ \\
\hline More than I race & 2.34 & $<0.0001$ & $1.74-3.15$ \\
\hline Native American Indian & 1.55 & 0.066 & $0.97-2.46$ \\
\hline $\begin{array}{l}\text { Native Hawaiian or Pacific } \\
\text { Islander }\end{array}$ & 2.82 & 0.162 & $0.66-12.08$ \\
\hline Other Race & 0.68 & $<0.0001$ & $0.60-0.77$ \\
\hline \multicolumn{4}{|l|}{ Specialty } \\
\hline Comprehensive & \multicolumn{3}{|c|}{ Reference category } \\
\hline Cornea & 0.93 & 0.050 & $0.87-1.00$ \\
\hline Resident or Fellow & 1.03 & 0.735 & $0.89-1.19$ \\
\hline Glaucoma & 0.93 & 0.037 & $0.87-1.00$ \\
\hline Injection & 5.94 & 0.088 & $0.77-46.03$ \\
\hline Laser & \multicolumn{3}{|c|}{ Only I observation } \\
\hline Neuro & 1.83 & $<0.0001$ & $1.5 \mathrm{I}-2.22$ \\
\hline Optometry & 0.47 & $<0.0001$ & $0.35-0.65$ \\
\hline Other & 0.50 & 0.276 & $0.14-1.75$ \\
\hline Plastics & 0.83 & 0.141 & $0.66-1.06$ \\
\hline Post-op & \multicolumn{3}{|c|}{ Only I observation } \\
\hline Strabismus & 0.91 & 0.059 & $0.83-1.00$ \\
\hline Retina & 1.04 & 0.49 & $0.94-1.15$ \\
\hline \multicolumn{4}{|l|}{ Appointment Location } \\
\hline \multicolumn{4}{|c|}{ KEI General Detroit clinic location as reference category } \\
\hline Bingham Farms & 2.03 & $<0.0001$ & $1.80-2.29$ \\
\hline Clinton Township & 7.41 & $<0.0001$ & $3.48-15.81$ \\
\hline Dearborn & 2.71 & $<0.0001$ & $2.13-3.46$ \\
\hline Hutzel Warren & 3.00 & $<0.0001$ & $2.4 I-3.74$ \\
\hline KEI Dearborn Oakwood & 0.92 & 0.064 & $0.84-1.00$ \\
\hline KEI Dearborn Optometry & 1.72 & $<0.0001$ & $1.24-2.38$ \\
\hline KEI Adult Muscle & 0.80 & 0.022 & $0.66-0.97$ \\
\hline KEI Sinai Grace & 1.88 & $<0.0001$ & $1.33-2.67$ \\
\hline KEI Sinai Grace & 0.77 & $<0.000$ I & $0.69-0.87$ \\
\hline \multicolumn{4}{|l|}{ Ophthalmology } \\
\hline KEI Well Eye Care & 1.13 & 0.434 & $0.83-1.55$ \\
\hline Lake Orion & 5.78 & $<0.0001$ & $4.52-7.40$ \\
\hline Novi & 7.43 & $<0.0001$ & $3.57-15.49$ \\
\hline OR Boarding & 163.32 & $<0.0001$ & $23.33-1143.21$ \\
\hline
\end{tabular}

(Continued)
Table 3 (Continued).

\begin{tabular}{|c|c|c|c|}
\hline Predictor* & $\begin{array}{l}\text { Odds } \\
\text { Ratio }\end{array}$ & P-value & $95 \% \mathrm{Cl}$ \\
\hline Port Huron & 1.86 & $<0.0001$ & $1.44-2.40$ \\
\hline Residents & 1.15 & 0.095 & $0.98-1.34$ \\
\hline Southfield & 1.98 & $<0.0001$ & $1.80-2.18$ \\
\hline Taylor & 1.56 & $<0.0001$ & $1.29-1.89$ \\
\hline Troy & 2.27 & $<0.0001$ & $|.84-2.8|$ \\
\hline KEI Well Eye Clinic & 2.01 & $<0.0001$ & $\mathrm{I} .4 \mathrm{I}-2.86$ \\
\hline Ypsilanti & 6.51 & $<0.0001$ & $4.04-10.48$ \\
\hline \multicolumn{4}{|l|}{ Appointment Month } \\
\hline \multicolumn{4}{|c|}{ January month as reference category } \\
\hline February & 1.14 & $<0.0001$ & $|.07-1.2|$ \\
\hline March & 1.31 & & $1.21-1.42$ \\
\hline April & 1.37 & & $1.29-1.48$ \\
\hline May & 1.35 & & I.27-I.44 \\
\hline June & 1.26 & & $1.18-1.35$ \\
\hline July & 1.31 & & $1.21-1.43$ \\
\hline August & $\mathrm{I} .40$ & & $|.30-1.5|$ \\
\hline September & 1.26 & & $1.16-1.36$ \\
\hline October & 1.32 & & $1.23-1.42$ \\
\hline November & 1.30 & & $|.20-| .4 \mid$ \\
\hline December & 1.29 & & $1.19-1.39$ \\
\hline \multicolumn{4}{|l|}{ Model Characteristics } \\
\hline $\begin{array}{l}\text { Number of } \\
\text { Observations }\end{array}$ & \multicolumn{3}{|c|}{106,152} \\
\hline Prob> chi & \multicolumn{3}{|c|}{$<0.0000$ I } \\
\hline Pseudo R2 & \multicolumn{3}{|c|}{0.1610} \\
\hline Area under ROC curve & \multicolumn{3}{|c|}{0.75} \\
\hline
\end{tabular}

Notes: *Appointment compliance is the outcome (dependent) variable and race, age, sex, specialty, appointment location, month, and appointment rank are the predictors. Also, please note that 75 insurance categories have been omitted for table length but can be found in the supplementary materials.

Similarly, our comprehensive study, which focused on important characteristics such as demographics characteristics, can be used to identify compliant and non-compliant patients and provide vital insight into how the healthcare system can improve AC. Through this analysis, appointment attributes have been identified, which can be used to help improve patient's continuity of care.

African Americans were the primary ethnicity represented and among all non-compliant appointments represented the greatest share at $73.36 \%$. In contrast, Caucasian/White, Asian, and more than 1 race populations had greater AC with a 2.82, 1.89, 2.34 1.46, 1.41-, and 1.40-times greater odds of being compliant to any appointment, respectively $(\mathrm{p}<0.0001)$ (Table 3$)$. Our fully 


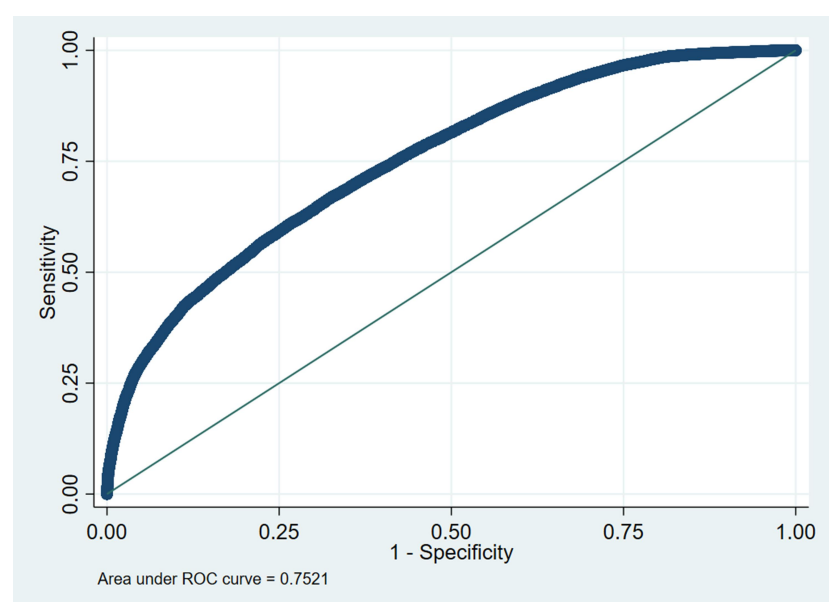

Figure 5 Receiver operating characteristic curve and associated AUC for logistic regressions across all appointments. Also refer Table 3 for detailed results.

adjusted model shows the locations in Detroit with the highest amount of AC were seen at Clinton Township (OR: 7.41) and Novi (OR: 7.43), relative to the Detroit KEI General location $(\mathrm{p}<0.0001)$ (Table 3$)$. The data in Table 1 illustrates the potential impact residents can have on AC. Although the data is not statistically significant, patients with appointments at resident clinics tend to have higher rates of NC. Falvo and Tippy ${ }^{22}$ assessed resident communication on conveying medication information to the patient's likelihood of following up for their next appointment. The analysis revealed that roughly $31 \%$ of patients were $\mathrm{AC}$, suggesting that who the patient was seeing impacted their compliance. ${ }^{22}$

Thompson et $\mathrm{al}^{23}$ explained that weather plays can affect $\mathrm{AC}$ on a particular day and influence follow up appointments. In our study, weather also proved to be an interesting factor that impacted AC. In Table 3, the impact of weather is seen as "Appointment Month", which shows that the odds of AC are significantly higher in the months of February to December, in comparison to the month of January $(\mathrm{p}<0.0001)$.

The highest number of appointments by specialty were seen in patients who required comprehensive, retina, or glaucoma appointments (Figure 1). Also, our study showed that patients with comprehensive and glaucoma appointments, had worse odds of being compliant as compared to patients with retina appointments (Table 3). Patients with glaucoma, retinal diseases, eg, diabetic retinopathy, and other chronic degenerative conditions that have a higher rate of blindness require consistent followup appointments to monitor progression. ${ }^{10,23}$ Interestingly, comprehensive appointments made up a higher percentage of all non-compliant appointments compared to compliant appointments (Table 1). Patients who are aware of having a chronic disease, such as glaucoma, are more likely to be adherent to their appointments. ${ }^{24}$ Because annual comprehensive appointments tend to serve as preventative visits, patients are more likely to be non-compliant. ${ }^{25}$

We observed that patient age $(\mathrm{p}<0.00001)$, but not gender, was an impactful factor on AC. Older patients were more compliant in comparison to younger populations. Many studies have shown that as age decreases, NC will increase. $^{14,26} \mathrm{NC}$ and gender have variable rates amongst the different disciplines. ${ }^{8,15,25,26}$ Younger patients may not be as adherent to their appointments due to more demanding obligations, such as those at work or to their family. At any given age, males are more likely to be compliant than females, but the effect of age increases with each additional year of life and for this reason age - particularly decades of age - is likely to be the more powerful predictor of compliance. It has been established that overall, women tend to use health services more than men- this trend may differ when it comes to specialty fields such as Ophthalmology. ${ }^{15,27,28}$

Additionally, appointments associated with patients who had the primary insurance providers Blue Shield of Michigan (PPO), Medicare, or Medicare plus Blue Shield, had a significantly higher rate of $\mathrm{AC}$ than Molina Associated insurances $(\mathrm{p}<0.0001)$. These results are consistent with a study, also conducted in metropolitan Detroit, where patients who had a Medicaid insurance provider were most associated with non-compliance. ${ }^{15}$ Similarly, a study conducted by the Illinois College of Optometry showed that the average percentage of patient no-shows at their clinic was $24.8 \%$ but rose to $41.25 \%$ for patients with Medicaid insurance. This also corroborates with our study's findings that younger patients are linked with non-compliance and patients from lower socioeconomic backgrounds are associated with multiple instances of NC. ${ }^{15,26,29}$

The strength of the physician-patient relationship is a powerful driver of $\mathrm{AC}$ and although this continuity of care is difficult to measure, our study attempts to quantify it through the implementation of the appointment rank variable. The calculated appointment rank shows that there was a greater mean appointment rank among all compliant appointments (10.10), in comparison to all noncompliant appointments (7.58) (Table 2). Also, the slightly higher median, range and interquartile range of appointment rank seen in compliant patients $(p<0.00001)$, 
suggests an increased length in the patient-physician history among compliant appointments.

Based on the results, appointment rank offers a possibility in measuring the continuity and quality of care, which can be a potential assessment tool for physicians. Many studies have investigated the impact of telephone and automated reminders on $\mathrm{AC}$, but this serves as a limitation in our study. ${ }^{7,19}$ There was no efficient way to control for this variable, as the retrospective data was pulled from an EMR system, encompassing a variety of KEI affiliated locations with different administration practices implemented at each location. In addition, the EMR system itself served as a limiting factor in this study due to potential glitches and the different administrative and provider input errors into the system. Thus, more efficient methods of ensuring EMR information accuracy need to be further investigated.

Another limitation to this study is where it was performed, which was limited by postal code. Although the study was conducted with patients from all over the state of Michigan, many patients were from metropolitan Detroit, a highly segregated region, suggesting some socioeconomic impact. It is difficult to appropriately measure socioeconomic factors, but literature has shown a striking difference in race and income level between varying locations. ${ }^{30}$ In the city of Detroit, $83 \%$ of the population is African American with a median household income of $\$ 30,344 .{ }^{30}$ In the suburb of West Bloomfield, $79 \%$ of the population is Caucasian and the median household income is $\$ 114,711$ as of $2017 .{ }^{31}$ Even though other metropolitan cities in the United States may be similar in that regard, it is challenging to generalize the results from KEI to most of the U.S, but it has been attempted with the zip code inclusion criteria. Another limitation was the sheer number of appointments used for this study. Due to these large numbers, many comparisons could show statistical significance without any true statistical significance. We countered this by strengthening the exclusion criteria (Figure 1).

This comprehensive study encompassed a set of general parameters that shaped a reliable model to predict AC. This is reflected by our AUC values of $75 \%$ described in both Table 3 and Figure 5. This exceeds the commonly accepted minimum AUC threshold of $70 \%$. Nevertheless, this model can be improved.

In future analyses, additional metrics, such as driving distance, access to transportation, and patient satisfaction, could increase the predictive accuracy of our model. ${ }^{21}$
Hence, a follow-up study can be performed to overcome this limitation and analyze subsets and more patientspecific characteristics (employment status, education, household income, history of mental illness, nonophthalmologic comorbidities and primary method of transportation) that could, perhaps, contribute to noncompliance. Also, the inclusion criteria that focuses onto an adult population and only looks at arrival vs no show, can be expanded upon in the future to assess compliance in pediatric groups and the potential impact of cancellations. These factors may provide insight as to where an Ophthalmology appointment lies in the priorities of a patient's life, as well as information on whether patients have the necessary resources available to establish continuity of care with a physician.

\section{Conclusions}

This investigation found the distribution of AC, defined by the $\mathrm{CO}$ and $\mathrm{NC}$ groups, to be significantly different across patient gender, race, age at appointment, clinic location, and appointment month, and physician specialty. Hence, the comprehensive dataset reveals potential factors that affect $\mathrm{AC}$ and can be used to improve the quality of patient care. This study has applicability to other institutions, allowing for the assessment of patient care and overall satisfaction.

\section{Acknowledgments}

This study is supported in part by an unrestricted grant from Research to Prevent Blindness to Mark S. Juzych, M. D. (Kresge Eye Institute/Department of Ophthalmology, Visual, and Anatomical Sciences, Wayne State University School of Medicine). The research in the department is also supported by NIH center grant P30EY004068. Kumar laboratory is supported by NIH grants R01EY026964, R01EY027381, and 1R21AI140033. The funders had no role in study design, data collection, and interpretation, or the decision to submit the work for publication. Authors would like thank Mr. Chaesik Kim for his help in tabulation of data from medical records. The preliminary findings reported in the study was presented at the annual meeting of the Association of Research in Vision and Ophthalmology (ARVO). The published abstract is available at:

Link: https://iovs.arvojournals.org/article.aspx?arti cleid $=2769252]$. 


\section{Author Contributions}

All authors made a significant contribution to the work reported, whether that is in the conception, study design, execution, acquisition of data, analysis, and interpretation. All authors were involved in drafting, revising, and critically reviewing the article; gave final approval of the version to be published; have agreed on the journal to which the article has been submitted; and agree to be accountable for all aspects of the work.

\section{Disclosure}

All authors declared no conflicts of interest in this work.

\section{References}

1. Kerse N, Buetow S, Mainous AG, Young G, Coster G, Arroll B. Physician-patient relationship and medication compliance: a primary care investigation. Ann Fam Med. 2003;2(5):455-461. doi:10.1370/ afm. 139

2. Santoso JT, Yibirin E, Crigger M, et al. Incidence and contributing factors to termination of the patient-physician relationship. Gynecol Oncol Rep. 2016;17:42-44. doi:10.1016/j.gore.2016.05.011

3. Physicians, A.A.o.F. Definition of: continuity of care; 2015. Available from: http://www.aafp.org/about/policies/all/definitioncare.html. Accessed February 23, 2021.

4. Kim SY. Continuity of Care. Korean J Fam Med. 2017;38(5):241. doi:10.4082/kjfm.2017.38.5.241

5. Kim J-H, Park E-C, Kim TH, et al. Hospital charges and continuity of care for outpatients with hypertension in South Korea: a nationwide population-based cohort study from 2002 to 2013. Korean J Fam Med. 2017;38(5):242-248. doi:10.4082/kjfm.2017.38.5.242

6. Sudhakar-Krishnan V, Rudolf MCJ. How important is continuity of care? Arch Dis Child. 2007;92(5):381-383. doi:10.1136/adc.2006.099853

7. Macharia WM, Leon G, Rowe BH, Stephenson BJ, Haynes RB. An overview of interventions to improve compliance with appointment keeping for medical services. JAMA. 1992;267(13):1813-1817. doi:10.1001/jama.1992.03480130129038

8. Nwabuo CC, Dy SM, Weeks K, et al. Factors associated with appointment non-adherence among African-Americans with severe, poorly controlled hypertension. PLoS One. 2014;9(8):e103090e103090. doi:10.1371/journal.pone.0103090

9. Peck CL, King NJ. Compliance and the doctor-patient relationship. Drugs. 1985;30(1):78-84. doi:10.2165/00003495-198530010-00008

10. Zebardast N, Solus JF, Quigley HA, et al. Comparison of resident and glaucoma faculty practice patterns in the care of open-angle glaucoma. BMC Ophthalmol. 2015;15(1):41. doi:10.1186/s12886-015-0027-x

11. Natarajan S. Advances in technology helps in early detection of vision disorders. Indian $J$ Ophthalmol. 2013;61(12):695-697. doi:10.4103/0301-4738.124733

12. Tatham AJ, Weinreb RN, Medeiros FA. Strategies for improving early detection of glaucoma: the combined structure-function index. Clin Ophthalmol. 2014;8:611-621. doi:10.2147/OPTH.S44586

13. Lewis K. Improving patient compliance with diabetic retinopathy screening and treatment. Community Eye Health. 2015;28(92):68-69.

14. Jamous KF, Kalloniatis M, Hennessy MP, et al. Clinical model assisting with the collaborative care of glaucoma patients and suspects. Clin Exp Ophthalmol. 2015;43(4):308-319. doi:10.1111/ceo.12466
15. Miller AJ, Chae E, Peterson E, et al. Predictors of repeated "noshowing" to clinic appointments. Am J Otolaryngol. 2015;36 (3):411-414. doi:10.1016/j.amjoto.2015.01.017

16. Du Prel J-B. Choosing statistical tests: part 12 of a series on evaluation of scientific publications. Dtsch Arztebl Int. 2010;107 (19):343-348.

17. Capko J. The price you pay for missed appointments. J Med Pract Manage. 2007;22(6):368.

18. Husain-Gambles M, Neal RD, Dempsey O, et al. Missed appointments in primary care: questionnaire and focus group study of health professionals. Br J Gen Pract. 2004;54(499):108-113.

19. Phillips JD. Evaluating P Aluating Patient Compliance: E Atient Compliance: Effect of Appointment Reminder Ect of Appointment Reminder Systems on Attendance. Dayton, Ohio: Wright State University; 2008.

20. Smith DW, Vess J, Johnson E. Increasing follow-up rates at a free clinic. J Community Health Nurs. 2019;36(2):86-90. doi:10.1080/ 07370016.2019.1583842

21. Syed ST, Gerber BS, Sharp LK. Traveling towards disease: transportation barriers to health care access. $J$ Community Health. 2013;38 (5):976-993. doi:10.1007/s10900-013-9681-1

22. Falvo D, Tippy P. Communicating information to patients. Patient satisfaction and adherence as associated with resident skill. $J$ Fam Pract. 1988;26(6):643-647.

23. Thompson AC, Thompson MO, Young DL, et al. Barriers to follow-up and strategies to improve adherence to appointments for care of chronic eye diseases. Invest Ophthalmol Vis Sci. 2015;56 (8):4324-4331. doi:10.1167/iovs.15-16444

24. Ashaye A, Adeoye A. Characteristics of patients who dropout from a glaucoma clinic. J Glaucoma. 2008;17(3):227-232. doi:10.1097/ IJG.0b013e31815768b3

25. Fudemberg SJ, Lee B, Waisbourd M, et al. Factors contributing to nonadherence to follow-up appointments in a resident glaucoma clinic versus primary eye care clinic. Patient Prefer Adherence. 2016;10:19-25. doi:10.2147/PPA.S89336

26. Hamilton W, Round A, Sharp D. Patient, hospital, and general practitioner characteristics associated with non-attendance: a cohort study. Br J Gen Pract. 2002;52(477):317-319.

27. Bertakis $K$. The influence of gender on the doctor-patient interaction. Patient Educ Couns. 2009;76(3):356-360. doi:10.1016/j.pec.2009.07.022

28. Redondo-Sendino A, Guallar-Castillón P, Banegas JR, et al. Gender differences in the utilization of health-care services among the older adult population of Spain. BMC Public Health. 2006;6(1):155. doi:10.1186/1471-2458-6-155

29. Ellis D, McQueenie R, McConnachie A, et al. Demographic and practice factors predicting repeated non-attendance in primary care: a national retrospective cohort analysis. Lancet Public Health. 2017;2 (p):e551-e559. doi:10.1016/S2468-2667(17)30217-7

30. Advameg I. Detroit, Michigan (MI) profile: population, maps, real estate, averages, homes, statistics, relocation, travel, jobs, hospitals, schools, crime, moving, houses, news, sex offenders; 2020 [cited May 16, 2020]. Available from: http://www.city-data.com/city/ Detroit-Michigan.html. Accessed February 23, 2021.

31. Advameg I. West Bloomfield Township, Michigan (MI 48323) profile: population, maps, real estate, averages, homes, statistics, relocation, travel, jobs, hospitals, schools, crime, moving, houses, news, sex offenders; 2020 [cited May 16, 2020]. Available from: http://www. city-data.com/city/West-Bloomfield-Township-Michigan.html. Accessed February 23, 2021. 


\section{Publish your work in this journal}

Patient Preference and Adherence is an international, peer-reviewed, open access journal that focusing on the growing importance of patient preference and adherence throughout the therapeutic continuum. Patient satisfaction, acceptability, quality of life, compliance, persistence and their role in developing new therapeutic modalities and compounds to optimize clinical outcomes for existing disease states are major areas of interest for the journal. This journal has been accepted for indexing on PubMed Central. The manuscript management system is completely online and includes a very quick and fair peer-review system, which is all easy to use. Visit http:// www.dovepress.com/testimonials.php to read real quotes from published authors. 